\title{
Pharmacokinetics and metabolism of ifosfamide in relation to DNA damage assessed by the COMET assay in children with
}

\section{cancer}

\author{
I Willits', L Price', A Parry 4 , MJ Tilby', D Ford ${ }^{2}$, S Cholerton ${ }^{3}$, ADJ Pearson ${ }^{4,5}$ and AV Boddy \\ 'Northern Institute for Cancer Research, University of Newcastle, Newcastle upon Tyne NE2 4HH, UK; ${ }^{2}$ School of Biomedical Sciences, University of \\ Newcastle, Newcastle upon Tyne NE2 4HH, UK; ${ }^{3}$ School of Medical Education Development, University of Newcastle, Newcastle upon Tyne NE2 4HH, \\ UK; ${ }^{4}$ School of Clinical Medical Sciences, University of Newcastle, Newcastle upon Tyne NE2 4HH, UK; ${ }^{5}$ Paediatric Oncology, Royal Victoria Infirmary, \\ Newcastle upon Tyne, UK
}

The degree of damage to DNA following ifosfamide (IFO) treatment may be linked to the therapeutic efficacy. The pharmacokinetics and metabolism of IFO were studied in 19 paediatric patients, mostly with rhabdomyosarcoma or Ewings sarcoma. Ifosfamide was dosed either as a continuous infusion or as fractionated doses over 2 or 3 days. Samples of peripheral blood lymphocytes were obtained during and up to $96 \mathrm{~h}$ after treatment, and again prior to the next cycle of chemotherapy. DNA damage was measured using the alkaline COMET assay, and quantified as the percentage of highly damaged cells per sample. Samples were also taken for the determination of IFO and metabolites. Pharmacokinetics and metabolism of IFO were comparable with previous studies. Elevations in DNA damage could be determined in all patients after IFO administration. The degree of damage increased to a peak at $72 \mathrm{~h}$, but had returned to pretreatment values prior to the next dose of chemotherapy. There was a good correlation between area under the curve of IFO and the cumulative percentage of cells with DNA damage $\left(r^{2}=0.554, P=0.004\right)$, but only in those patients receiving fractionated dosing. The latter patients had more DNA damage (mean \pm s.d., 2736 \pm 597 ) than those patients in whom IFO was administered by continuous infusion ( $1453 \pm 730$ ). The COMET assay can be used to quantify DNA damage following IFO therapy. Fractionated dosing causes a greater degree of DNA damage, which may suggest a greater degree of efficacy, with a good correlation between pharmacokinetic and pharmacodynamic data.

British Journal of Cancer (2005) 92, I626- 1635. doi:I0.1038/sj.bjc.6602554 www.bjcancer.com

Published online 12 April 2005

(c) 2005 Cancer Research UK

Keywords: ifosfamide; comet; DNA damage; paediatric

Ifosfamide (IFO) is used in the treatment of a variety of paediatric tumours, especially sarcomas, and is usually combined with a number of different agents such as vincristine, actinomycin $\mathrm{D}$ or doxorubicin (Carli et al, 2003). Although it is considered to be an analogue of cyclophosphamide, IFO appears to have specific activity in some tumour types, for example, rhabdomyosarcoma (Breneman et al, 2003). Like cyclophosphamide, IFO requires metabolic activation, mediated by cytochrome $P 450$ enzymes (Walker et al, 1994), initially forming a 4-hydroxy metabolite, which spontaneously releases the active form - isophosphoramide mustard (IPM). Competing pathways for IFO metabolism result in inactive, dechloroethylated metabolites (2-dechloroethylifosfamide (2DCI) and 3-dechloroethylifosfamide (3DCI)) (Kerbusch et al, 2001a). In addition, up to $20 \%$ of a dose of IFO can be recovered unchanged in the urine. So, in contrast to cyclophosphamide where $90 \%$ of a dose is activated, as much as $70 \%$ of a dose of IFO may be eliminated by inactivating

*Correspondence: Dr A Boddy; E-mail: alan.boddy@ncl.ac.uk Received 3 November 2004; revised 10 January 2005; accepted 7 March 2005; published online 12 April 2005 pathways. An intermediate on the activation pathway is also subject to metabolic inactivation, aldoifosfamide being further oxidised to an inactive carboxy form by aldehyde dehydrogenases (Dockham et al, 1992).

The cytotoxic effect of IFO is thought to be mediated by the reaction of IPM, via unstable aziridine intermediates, with nucleophilic bases of DNA (Sladek, 1988). As a bifunctional alkylating agent, IFO is able to form inter- and intrastrand crosslinks, as well as crosslinks between DNA and protein. Previous studies have shown that the DNA damage caused by IFO in its activated form is detectable by COMET analysis (Johnstone et al, 2000). This method, also known as single-cell gel electrophoresis, determines the degree of fragmentation of DNA caused by a particular agent under alkali or neutral conditions (Fairbairn et al, 1995; Rojas et al, 1999). COMET analysis of the IFO-induced DNA damage has been applied to MCF-7 breast cancer cells in vitro and to peripheral blood lymphocytes (PBL) and breast tumour cells from patients (Johnstone et al, 2000). Another application of COMET to the analysis of IFO DNA interactions is the detection of crosslink formation, as these retard DNA migration after exposure of PBL to ionising radiation (Hartley et al, 1999). 
In paediatric patients, the metabolism and pharmacokinetics of IFO have been extensively studied (Boddy et al, 1993, 1995b; Silies et al, 1998; Kerbusch et al, 2001a-c; Misiura et al, 2003). No direct correlation has been found between pharmacokinetic parameters of drug or metabolites and clinical outcome (Kerbusch et al, 2001d). It may, therefore, be appropriate to consider an intermediate measure of IFO action such as the degree of DNA damage in PBL. In the current study, PBL from 19 patients have been collected at various times after IFO administration. Data from COMET analysis has been compared to pharmacokinetic parameters. In addition, COMET analysis of DNA damage in vitro has been performed, to investigate the relationship between DNA damage and antiproliferative effect.

\section{PATIENTS AND METHODS}

Ifosfamide and its metabolites were the kind gift of Dr Jürg Pohl, ASTA Medica, Germany. All other reagents were obtained from Sigma, Poole, Dorset, UK, except where otherwise indicated, and were of an appropriate analytical grade.

In all, 19 patients (five female) aged between 2 and 19 years were recruited to the study. In each case, informed written consent was obtained from the patient and/or parent, as appropriate, and the study was approved by the ethical committee of the Newcastle Hospitals Trust. Details of patient characteristics, including the protocol that the patients received, IFO dose and schedule are given in Table 1. Of these patients, eight were studied after a second dose of IFO in order to assess the degree of intersubject variability in DNA damage. Treatment was the same on the two courses studied.

Ifosfamide was administered either as a continuous infusion over 3 days $(n=8)$ or as a $3 \mathrm{~h}$ infusion every $24 \mathrm{~h}$ for 3 days $(n=5)$. Three patients were treated with just 2 consecutive days of fractionated dosing and three received 3 consecutive days of IFO, but with a $1 \mathrm{~h}$ infusion time. No attempt was made to control concurrent medication, but a record was kept of potential interacting drugs (Table 1).

For those patients receiving a $3 \mathrm{~h}$ infusion of IFO, blood samples were taken for the determination of IFO and its metabolites before administration, then at 1.5 and $3 \mathrm{~h}$ during the infusion and at 0.5 , $1,2,4,612$ and $24 \mathrm{~h}$ after the end of infusion. Patients with a $1 \mathrm{~h}$ infusion had a pretreatment and end of infusion samples taken together with the postinfusion samples as for a $3 \mathrm{~h}$ infusion. Sampling was repeated for each day of drug administration. For those patients receiving a continuous infusion of IFO, sample times were pretreatment, $3,6,12,18,24,36,48,60$ and $72 \mathrm{~h}$ during the infusion. Samples were also taken at 2, 4, 6, 12, 18 and $24 \mathrm{~h}$ after the end of the infusion.

Plasma was separated by centrifugation at $1500 \mathrm{~g}$ and stored frozen at $-20^{\circ} \mathrm{C}$ until subsequent analysis. Ifosfamide, 2DCI, 3DCI and carboxyifosfamide were determined by a validated highperformance thin-layer chromatography method (Boddy and Idle, 1992). A minor metabolite, 4-ketoifosfamide, was detected in some patients, but could not be consistently quantified. Noncompartmental methods were used to estimate pharmacokinetic parameters for parent drug as described previously (Boddy et al, 1995b), and the linear trapezoidal rule was used to calculate area under the curve (AUC) for parent drug and metabolites. Area under the curve values for the continuous infusion data relate to all 3 days of administration, including data after the end of infusion.

In addition to samples collected for pharmacokinetic analysis, whole blood samples were taken prior to treatment, and at 3 and $24 \mathrm{~h}$ after each dose. A final sample was taken prior to the next course of treatment, that is, 3 weeks after the start of the initial course. The sampling times were based on previous data

Table I Patient details

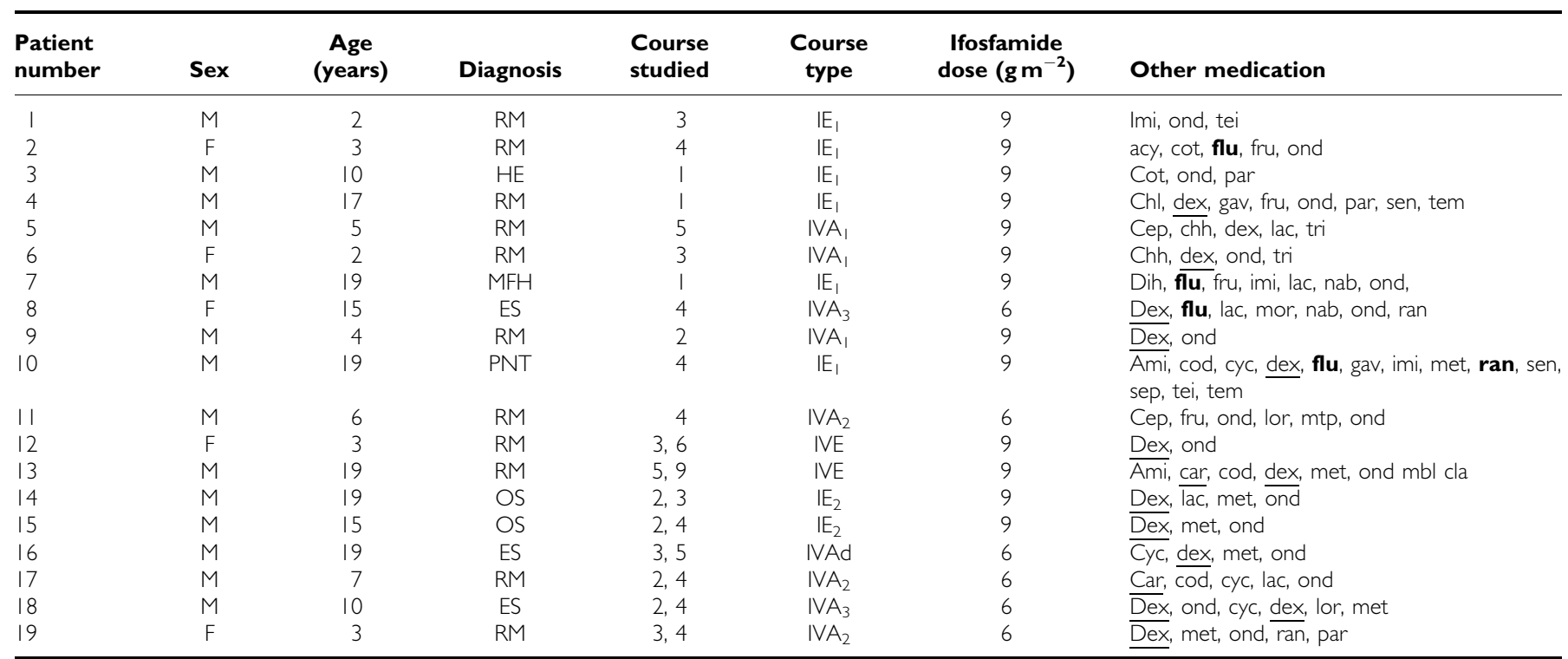

Diagnosis: $\mathrm{ES}=$ Ewings sarcoma; $\mathrm{HE}=$ haemangioendothelioma; $\mathrm{MFH}=$ malignant fibrous histiocytoma; $\mathrm{PNT}=$ primitive neuroectodermal tumour; $\mathrm{OS}=$ osteogenic sarcoma; $\mathrm{RM}=$ rhabdomyosarcoma. Course type: $\mathrm{IE}_{1}$ - ifosfamide $3 \mathrm{~g} \mathrm{~m}^{-2}$ day $^{-1}$ continuous infusion over 3 days. Etoposide $200 \mathrm{mg} \mathrm{m}^{-2}$ day $^{-1}$ as a $2 \mathrm{~h}$ infusion on 3 consecutive days. IE $\mathrm{E}_{2}-$ as $\mathrm{IE}_{\mathrm{I}}$, etoposide $150 \mathrm{mg} \mathrm{m}^{-2} \mathrm{day}^{-1}$. IVA 1 - ifosfamide $3 \mathrm{~g} \mathrm{~m}^{-2}$ day $^{-1}$ as a $3 \mathrm{~h}$ infusion on 3 consecutive days. Actinomycin $\mathrm{D}$ and vincristine both $1.5 \mathrm{mg} \mathrm{m} \mathrm{m}^{-2}$ bolus on day I only. $\mathrm{IVA}_{2}$ - as IVA, ifosfamide on 2 days only. IVA $A_{3}$ - as IVA , ifosfamide $2 \mathrm{~g} \mathrm{~m}^{-2}$ day ${ }^{-1}$ I h infusion on 3 consecutive days. IVAd - as IVA $\mathrm{A}_{3}$, but adriamycin $20 \mathrm{mg} \mathrm{m}^{-2}$ day ${ }^{-1}$ as a $6 \mathrm{~h}$ infusion on 3 consecutive days, no actinomycin D. IVE - ifosfamide $3 \mathrm{~g} \mathrm{~m}^{-2}$ day ${ }^{-1}$ as a $3 \mathrm{~h}$ infusion, etoposide $150 \mathrm{mg} \mathrm{m}^{-2}$ as a $4 \mathrm{~h}$ infusion, each on 3 consecutive days. Vincristine $1.5 \mathrm{mg} \mathrm{m}^{-2}$ bolus on day I only. Other medication (drugs taken during study): Acy = acyclovir; amy=amitriptyline; car = carbamazepine; cep =cephalexin; chh =chloral hydrate; $\mathrm{chl}=$ chlorpromazine; $c$ la = clarithromycin; $\operatorname{cod}=$ codeine phosphate; $\cot =$ cotrimoxazole; $c y c=$ cyclozine; dex = dexamethasone; dih=dihydrocodeine; dox= doxorubicin; flu = fluconazole; fru = frusemide; gav = gaviscon; imi = imipenem; lac = lactulose; lar =lorazepam; $\mathrm{mbl}=$ methlyene blue; met = metoclopropamide; $\mathrm{mtp}=$ methotrimeprazine; mor = morphine sulphate; $\mathrm{nab}=$ nabilone; ond = ondansetron; par = paracetamol; ran = ranitidine; sen = senna; tei $=$ teicoplanin; tem =temazepam; tri = trimeprazine. Drugs thought to inhibit CYP3A4 are shown in bold, drugs known to induce CYP3A4 are underlined. All patients were also hydrated with mesna at an equivalent dose to ifosfamide (2 or $3 \mathrm{~g} \mathrm{~m}^{-2} \mathrm{day}^{-1}$ in $3 \mathrm{l}$ ). This was administered as a continuous infusion throughout the course and for $12 \mathrm{~h}$ after completion of the course. 
(Johnstone et al, 2000). Patients who were studied on more than one course of treatment had a second set of blood samples taken for pharmacokinetic and COMET analysis.

The COMET assay was performed as described previously (Johnstone et al, 2000). Peripheral blood lymphocytes were isolated at the time of blood sampling using Lymphoprep. Storage of PBLs was at $-80^{\circ} \mathrm{C}$, and analysis was always completed within 1 month of sampling. Stability studies indicated that there was no change in the measurement of DNA damage using the COMET assay during 1 month of sample storage. The degree of DNA damage in a given patient sample or in vitro investigation was quantified by measuring the distributed tail moment (TM) in a minimum of 30 cells per slide. Images were analysed using the COMOS image analysis software (Biorad Laboratories, Hertfordshire, UK). The TM data were log normalised and a logarithmic mean and standard deviation (s.d.) determined. The number of highly damaged (HD) cells (log TM more than $2 \times$ s.d. from the mean) per sample was calculated. To estimate the overall degree of DNA damage caused during a cycle of chemotherapy, the AUC of percentage of HD cells (AUCHD) per sample plotted against time was calculated. An internal standard of CCRF-CEM cells that had received a standard dose of radiation was included as a control in each COMET experiment.

In order to provide some background to the clinical studies, the effect of IFO and its active metabolites on the formation of COMET-detectable DNA damage in vitro was investigated. CCRFCEM leukaemia cells were exposed to varying concentrations of the precursor of the active 4-hydroxy metabolite (4-hydroperoxyifosfamide) or IPM for up to $72 \mathrm{~h}$, although these unstable metabolites break down quickly in the medium. Growth inhibition was determined by counting the cells using a Coulter counter and was compared to the degree of DNA damage, as measured by the COMET assay. AUCHD was determined by measuring the percentage of HD cells at times 1, 24, 48 and $72 \mathrm{~h}$ after the start of drug exposure.

Statistical analysis was performed using Graphpad Prism, version 3 (Graphpad, San Diego USA). Differences between treatments were analysed using one-way analysis of variance and relationships between pharmacokinetic parameters and DNA damage measurements were analysed by linear regression.

\section{RESULTS}

\section{Pharmacokinetics and metabolism of IFO}

The pharmacokinetic parameters and AUC values for IFO and its metabolites are given in Table 2. As reported previously (Boddy et al, 1995b; Kerbusch et al, 2001c), apparent clearance is greater in those patients receiving a continuous infusion (median $6.21 \mathrm{~h}^{-1} \mathrm{~m}^{-2}$ ) compared to day 1 of fractionated dosing (median $4.1 \mathrm{l} \mathrm{h}^{-1} \mathrm{~m}^{-2}$ ). However, induction of metabolism is also apparent on day 3 of the fractionated schedule with an increase in median clearance from 4.1 to $6.11 \mathrm{~h}^{-1} \mathrm{~m}^{-2}$. Correspondingly, the half-life of IFO was longest after a single $3 \mathrm{~h}$ infusion, and decreased with repeated dosing or after a continuous infusion. The total AUC of the parent drug was not different in those patients having fractionated dosing over 3 days compared to those receiving a continuous infusion and there was no difference in the AUCs of the metabolites comparing the two groups. Although two patients (Nos. 13 and 17) were being treated with the enzyme-inducing anticonvulsant carbamazepine and four (Nos. 2, 7, 8 and 10) were being treated with fluconazole, which may inhibit IFO metabolism, none of these patients had remarkably high or low clearance values. Similarly, plasma concentrations of metabolites were not markedly different for these patients.

\section{COMET analysis of DNA damage following IFO administration}

There was some variation in the degree of DNA damage present in the pretreatment samples of patients receiving IFO for paediatric malignancies. The median TM for all COMETs within an analysis varied from 2 to 13 (arbitrary units), while the percentage of HD cells varied from 1 to $13 \%$ of the total. There was no correlation between the apparent amount of COMET-detectable DNA damage and the number of prior courses of chemotherapy or the age of the patient. The patient with the highest degree of pretreatment damage was patient 16 , who was a known cigarette smoker. The effect of cigarette smoking on COMET-detectable DNA damage has been noted previously (Hininger et al, 2004).

An increase in the degree of damaged DNA was apparent in post-treatment samples from all patients studied (Figures $1 \mathrm{~A}-\mathrm{F}$ and $2 \mathrm{~A}-\mathrm{F}$ ). The COMETs and accompanying histograms clearly show the evolution of DNA damage from pretreatment levels to the maximum degree of DNA damage $72 \mathrm{~h}$ after the start of administration, for both 72-h infusion and fractionated dosing over 3 days. In both cases, some degree of resolution of damage was apparent $96 \mathrm{~h}$ after the start of administration, and DNA damage had returned to pretreatment values prior to the next course of IFO.

The percentage of HD cells was chosen as a summary parameter for the degree of DNA damage in each patient sample. Analysis based on median TM or other measures of damage did not differ qualitatively from that based on HD. Plots of percent HD against time, superimposed on plasma concentration-time profiles, are shown in Figures 3 and 4 for representative patients who received either a continuous infusion or bolus administration, respectively. Almost all patients showed an accumulation of HD DNA during the time course of IFO administration, although for some patients a degree of resolution between doses on a fractionated regimen was apparent.

The relationship between overall DNA damage, as measured by the area under the percentage HD DNA vs time curve (AUCHD) and the pharmacokinetics of IFO, was explored. There was a strong

Table 2 Pharmacokinetics and metabolism of ifosfamide in the patients studied

\begin{tabular}{|c|c|c|c|c|c|c|c|c|}
\hline \multirow[b]{2}{*}{ Regimen } & \multirow[b]{2}{*}{$\mathbf{N}$} & \multicolumn{3}{|c|}{ IFO PK } & \multicolumn{4}{|c|}{ Metabolite AUCs $(\mu \mathrm{Mh})$} \\
\hline & & $\begin{array}{l}\text { Clearance } \\
\left(\mathbf{I h}^{-1} \mathbf{m}^{-2}\right)\end{array}$ & $t_{1 / 2}(h)$ & $V_{d}\left(1 \mathbf{k g}^{-1}\right)$ & IFO & CXI & 3DCI & 2DCl \\
\hline $\begin{array}{l}72 \mathrm{~h} \mathrm{Cl} \\
3 \text { or I h infusion day I } \\
3 \text { or I h infusion day } 3\end{array}$ & $\begin{array}{r}8 \\
11 \\
8\end{array}$ & $\begin{array}{l}6.2(2.6-7.4) \\
4.1(2.6-5.8) \\
6.1(3.0-7.8)\end{array}$ & $\begin{array}{l}2.4(1.3-5.6) \\
4.7(1.9-8.3) \\
2.9(2.0-4.6)\end{array}$ & $\begin{array}{l}0.44(0.16-1.82) \\
0.89(0.35-1.63) \\
0.92(0.53-1.33)\end{array}$ & $\begin{array}{l}5135(4668-13247) \\
6011(4009-9488)\end{array}$ & $\begin{array}{l}941(542-3443) \\
511(47-1700)\end{array}$ & $\begin{array}{l}\mid 868(554-5342) \\
\mid 702(52|-3| 64)\end{array}$ & $\begin{array}{l}1166(207-3011) \\
1337(326-2678)\end{array}$ \\
\hline
\end{tabular}

IFO-PK = pharmacokinetic parameters for ifosfamide; $t_{1 / 2}=$ half-life; $V_{d}=$ volume of distribution. For metabolite abbreviations see text. AUCs for IFO and metabolites in patients receiving a fractionated dosing over 3 days are given cumulatively over the cycle of chemotherapy to allow for comparison with data from patients receiving the same dose as a continuous $72 \mathrm{~h}$ infusion $(\mathrm{Cl})$. AUCs are dose adjusted in those patients receiving only 2 days of therapy. Data have been combined for those patients receiving fractionated doses of ifosfamide by either I or $3 \mathrm{~h}$ infusion. 

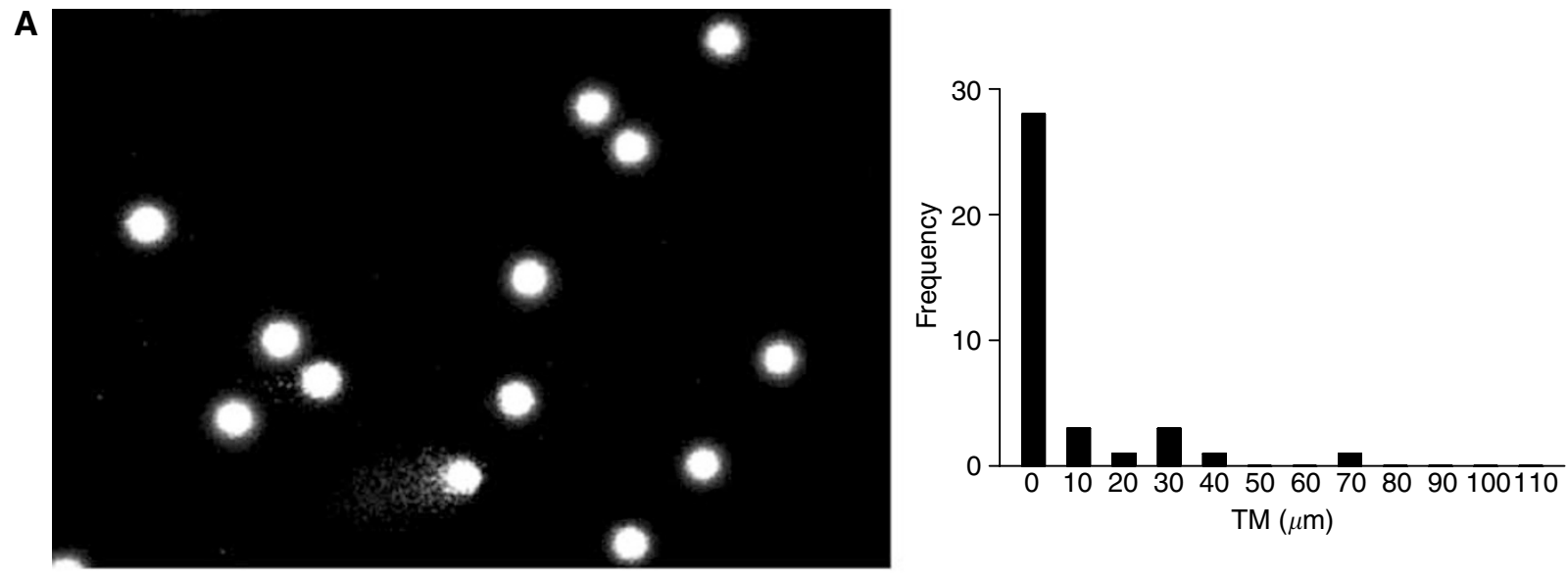

B
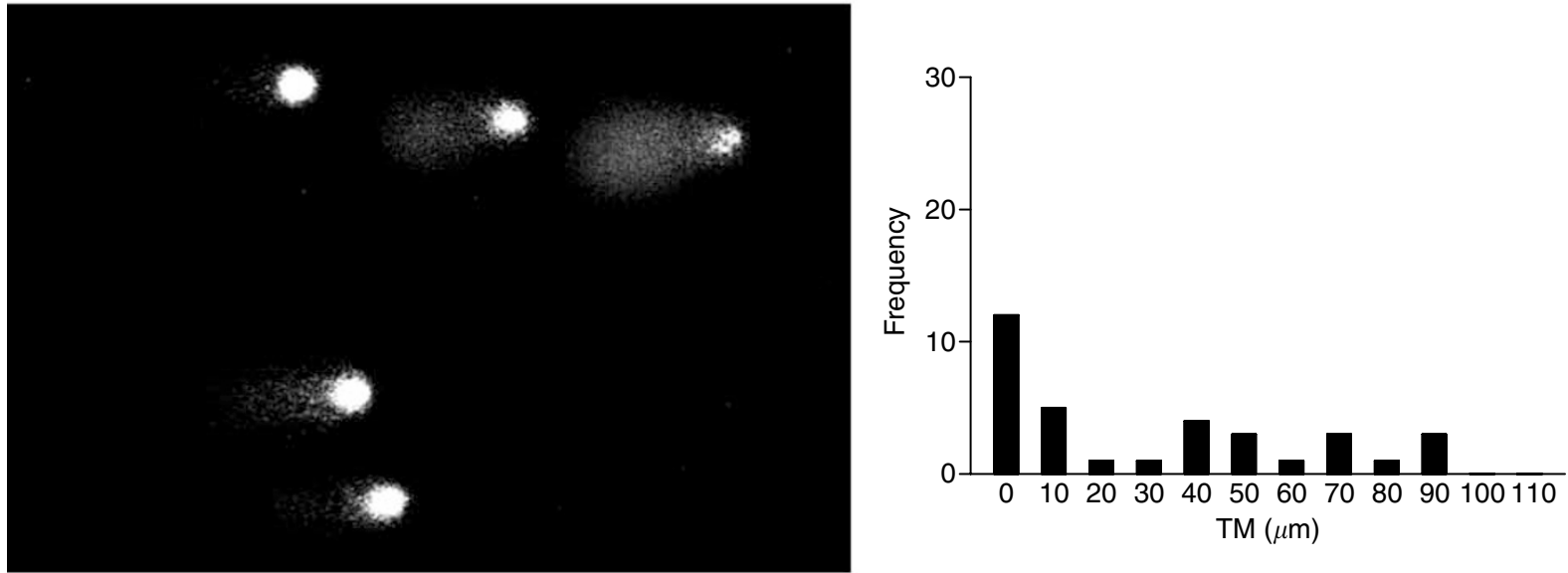

C
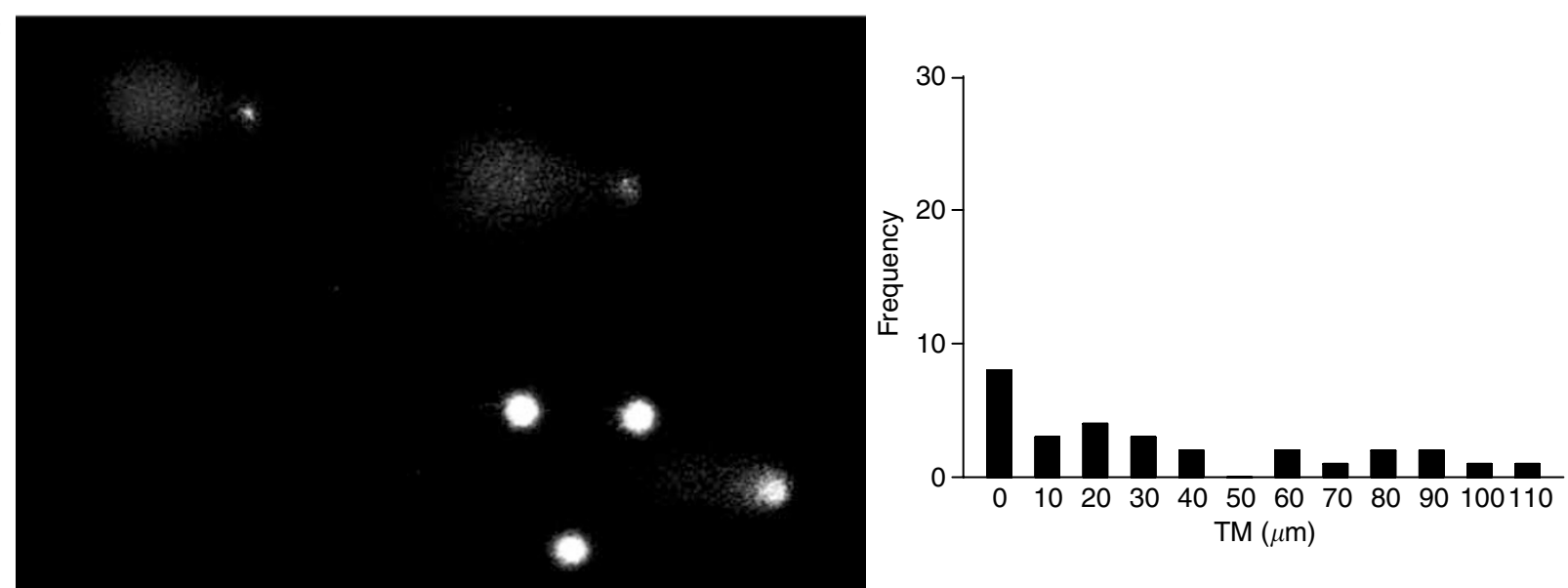

Figure I COMETs and histograms of tail moment (TM) for patient 14 , course 2. Ifosfamide, $9 \mathrm{~g} \mathrm{~m}^{-2}$ fractionated over 3 days, was administered as a $72 \mathrm{~h}$ continuous infusion. Pairs of figures show COMETs and histograms $(\mathbf{A})$ pretreatment, (B) $24 \mathrm{~h},(\mathbf{C}) 48 \mathrm{~h},(\mathbf{D}) 72 \mathrm{~h},(\mathbf{E}) 96 \mathrm{~h}$ and $(\mathbf{F}) 3$ weeks after the start of infusion.

positive correlation between the AUCHD and the total AUC of IFO when IFO was administered as a fractionated schedule over 2 or 3 days (Figure $5, r^{2}=0.556, P=0.004$ ). There was also a moderate correlation, in those patients receiving fractionated IFO, between AUCHD and the AUC of the inactive carboxy metabolite $\left(r^{2}=0.49\right.$, $P=0.023$ ), but there was no other relationship between the pharmacokinetics of IFO and COMET-detectable DNA damage.

Comparing DNA damage in PBL following IFO administration using either a continuous infusion or 3-day fractionated adminis- tration, it is clear that the latter regimen produces a higher AUCHD (Figure 6). The difference between treatment schedules was statistically significant $(P=0.0035$, one-way ANOVA), if the fractionated dosing data are restricted to those patients who received $9 \mathrm{~g} \mathrm{~m}^{-2}$, the same dose as the continuous infusion patients.

In those patients studied on more than one occasion, there was good correlation between the AUCHD determined on the two courses $\left(r^{2}=0.73\right)$. Also, there was no significant difference in the 
D
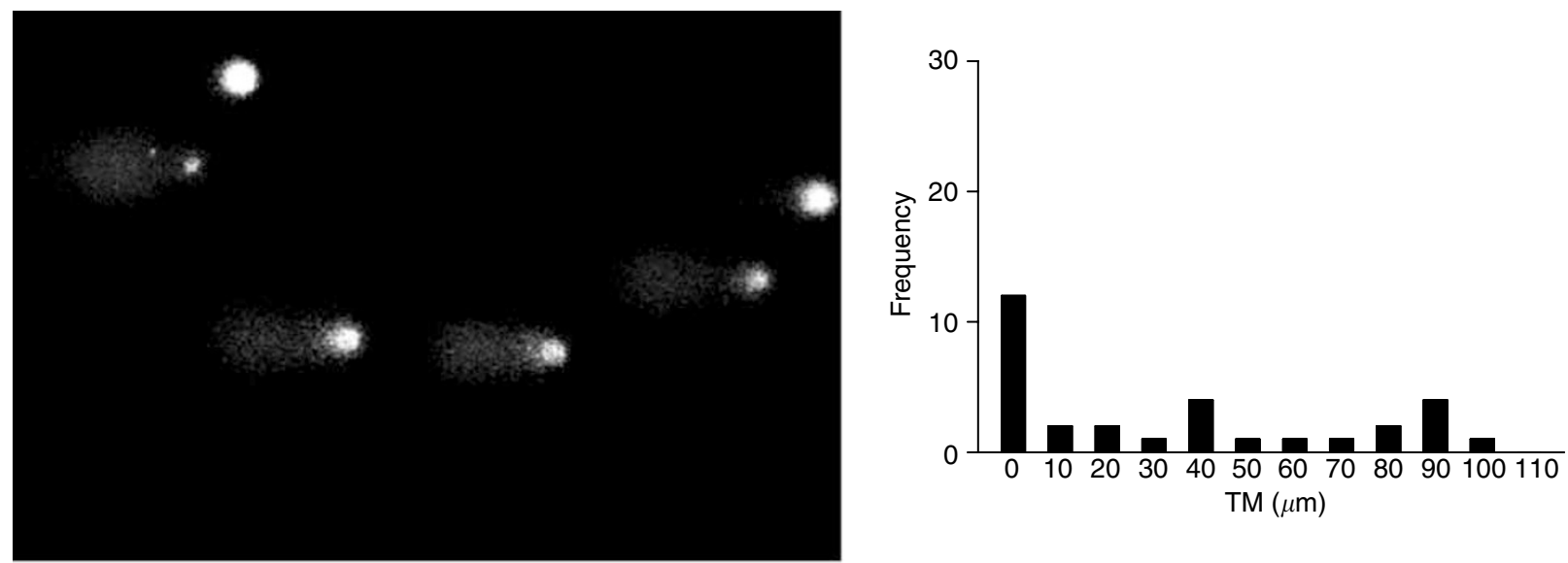

E
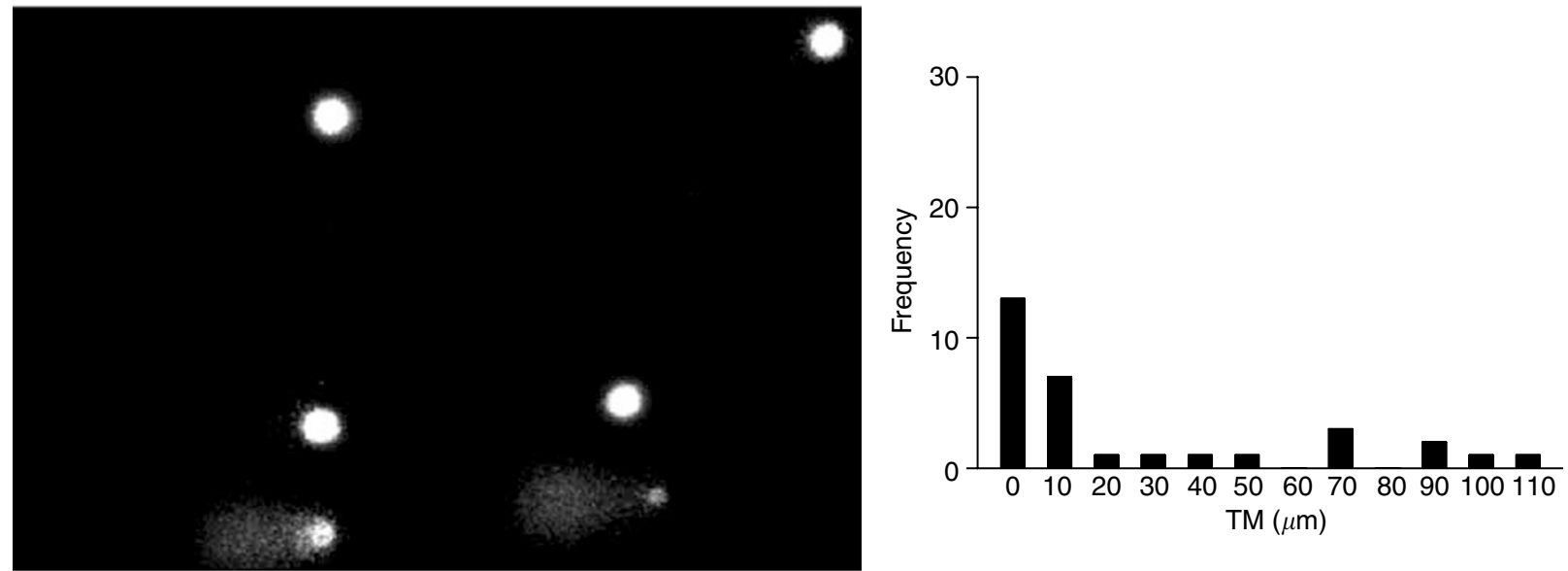

$\mathbf{F}$
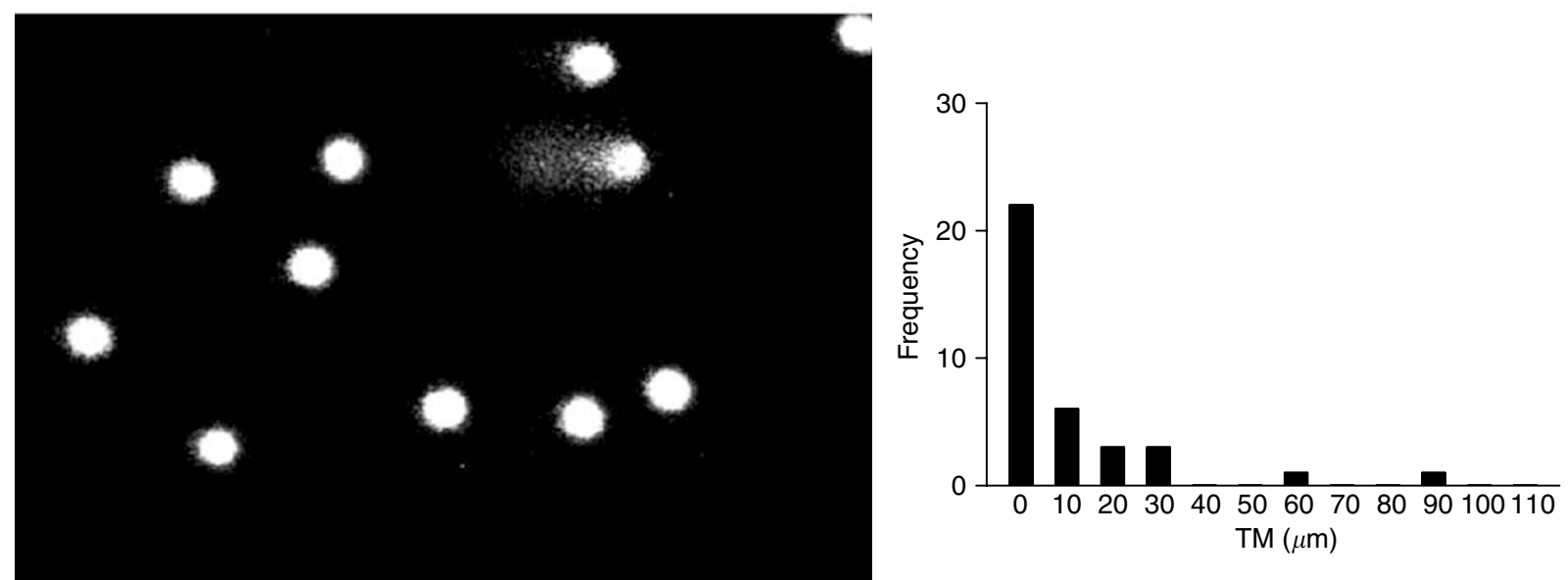

Figure I (Continued).

DNA damage observed between the two courses, with no indication of cumulative damage or of changes in sensitivity to treatment in successive courses (data not shown).

In vitro experiments with CCRF-CEM cells exposed to the active metabolites of IFO (4-hydroxy-IFO and -IPM) showed that the IC I $_{50}$ for 4-hydroxy-IFO $(19.6 \pm 1.5 \mu \mathrm{M})$ was much lower than that of IPM $(256 \pm 39 \mu \mathrm{M})$. However, at an $\mathrm{IC}_{50}$ concentration, the AUCHD for CCRF-CEM cells treated with either of the two agents were similar, and comparable to those seen in PBL in patients receiving IFO treatment (Table 3 ). Increasing the concentrations of the active metabolites to $4 \times \mathrm{IC}_{50}$ did not significantly elevate the AUCHD.

\section{DISCUSSION}

The role of IFO in treating paediatric malignancies has been the subject of some controversy (Kamen et al, 1995; Carli et al, 2003). As an alternative to cyclophosphamide, it seems to offer some benefits in terms of antitumour effect, but only at the expense of a wider spectrum of toxicity (Vela-Ojeda et al, 2000). While a great deal of research has focused on the metabolism of IFO in relation to side effects such as nephrotoxicity (Boddy et al, 1996) and neurotoxicity (Wainer et al, 1994), relatively little is known concerning the relationship between systemic pharmacology and 

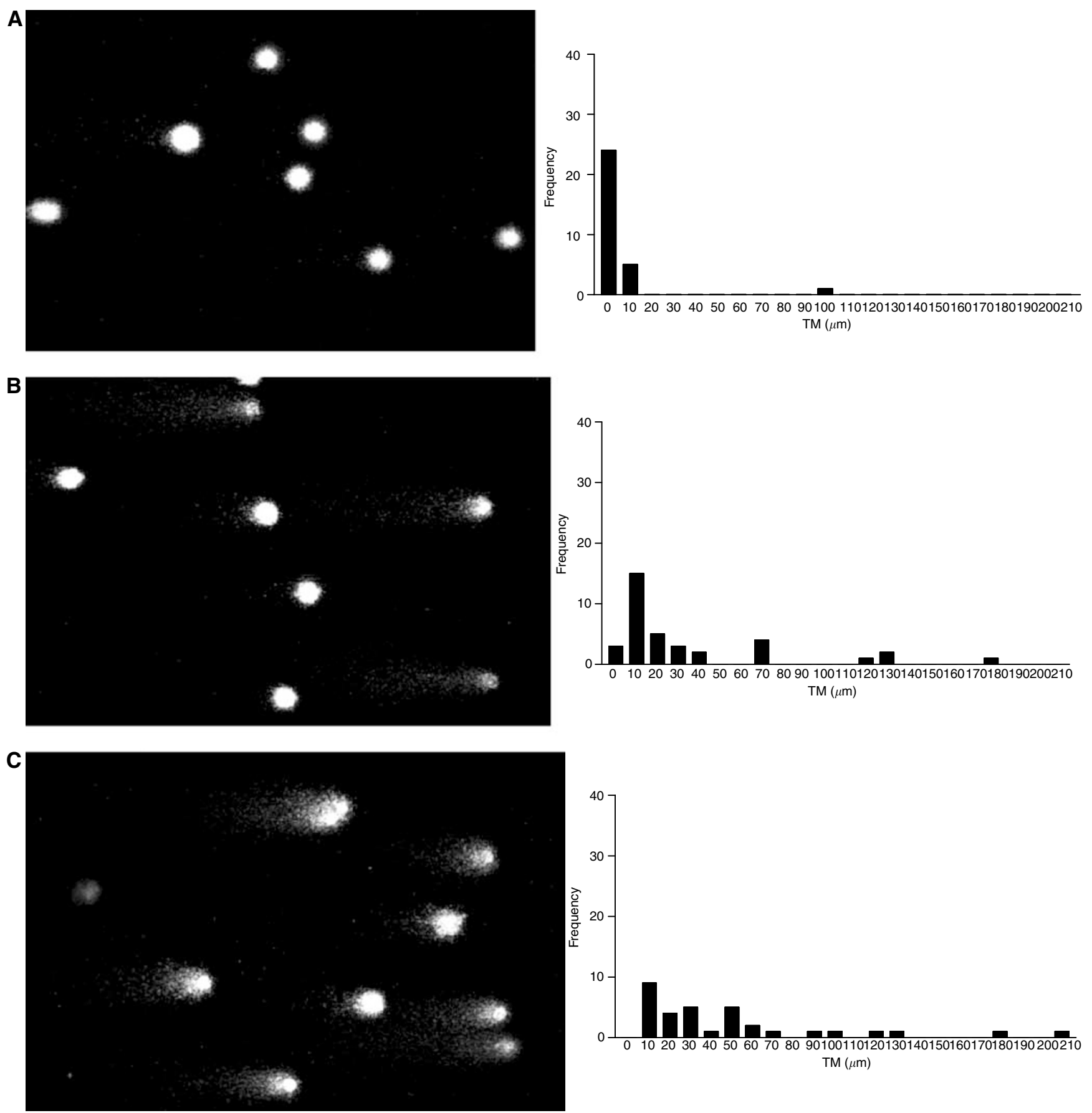

Figure 2 COMETs and histograms of tail moment (TM) for patient 9, course 2. Ifosfamide, $9 \mathrm{~g} \mathrm{~m}^{-2}$ fractionated over 3 days, was administered as a $3 \mathrm{~h}$ infusion each day. Pairs of figures show COMETs and histograms $(\mathbf{A})$ pretreatment, (B) $24 \mathrm{~h},(\mathbf{C}) 48 \mathrm{~h},(\mathbf{D}) 72 \mathrm{~h},(\mathbf{E}) 96 \mathrm{~h}$ and $(\mathbf{F}) 3$ weeks after the start of the first day of administration.

the drug interaction with its target, that is, DNA. Understanding of such relationships is complicated by the fact that IFO is a prodrug.

While it would be more relevant to measure the degree of DNA damage in the tumour, this is not practical in most clinical scenarios and there are both ethical and technical problems associated with such measurements. Peripheral blood lymphocytes represent a nonproliferating surrogate tissue; however, PBLs do allow for sequential measurements in the same patient and provide a measure of the systemic exposure to DNA-damaging species. We have previously applied this technique to breast cancer patients being treated with IFO, but had only limited success applying COMET analysis to tumour cells in fine-needle aspirates (Johnstone et al, 2000). The COMET method used here detects DNA strand breaks, presumably the result of repair processes or resulting from denaturing of DNA during the method itself (Rojas et al, 1999). Ifosfamide is thought to act by forming interstrand crosslinks in DNA and a method has been developed to use the COMET assay to measure such crosslinks directly (Hartley et al, 1999). That method was not applied here as it was not available at the start of the analysis and initial attempts to 

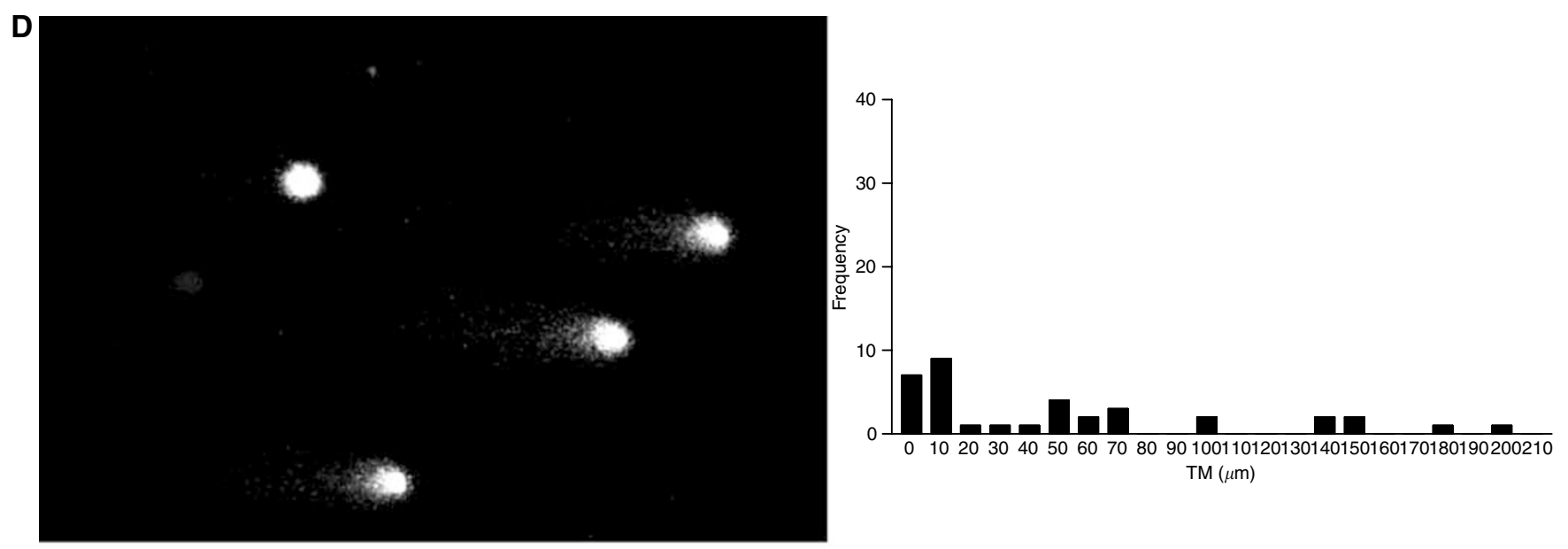

E
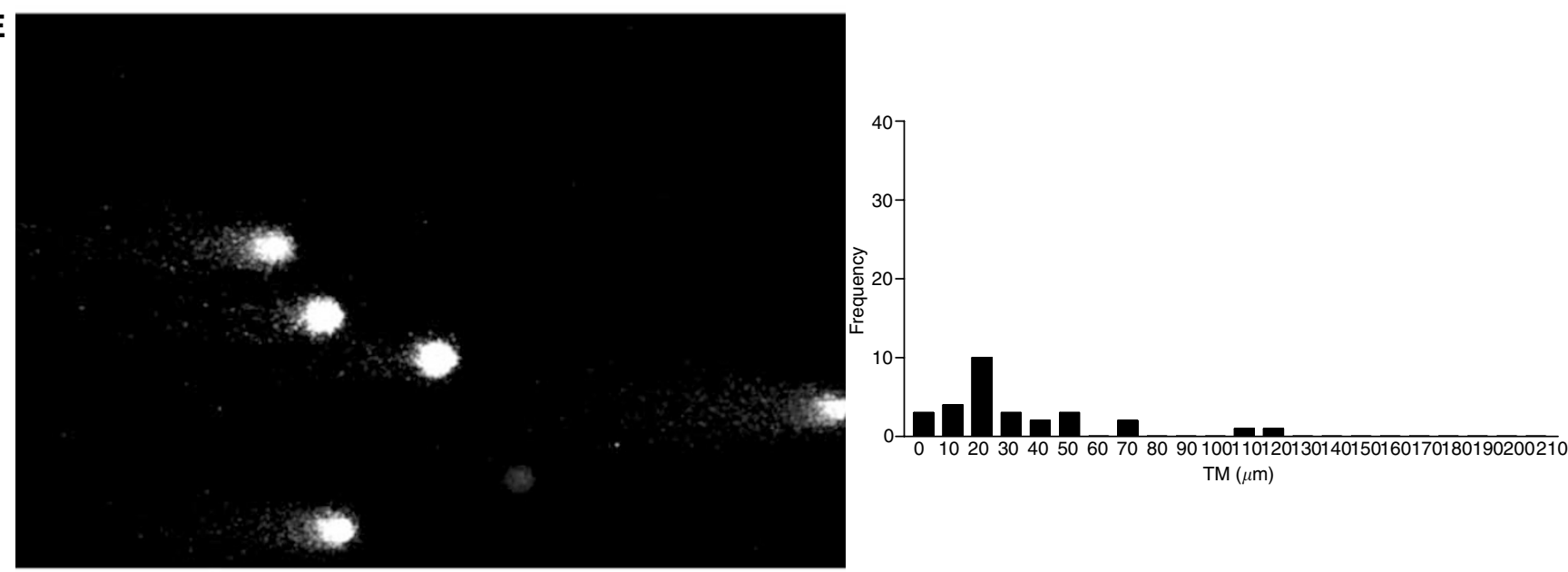

$\mathbf{F}$
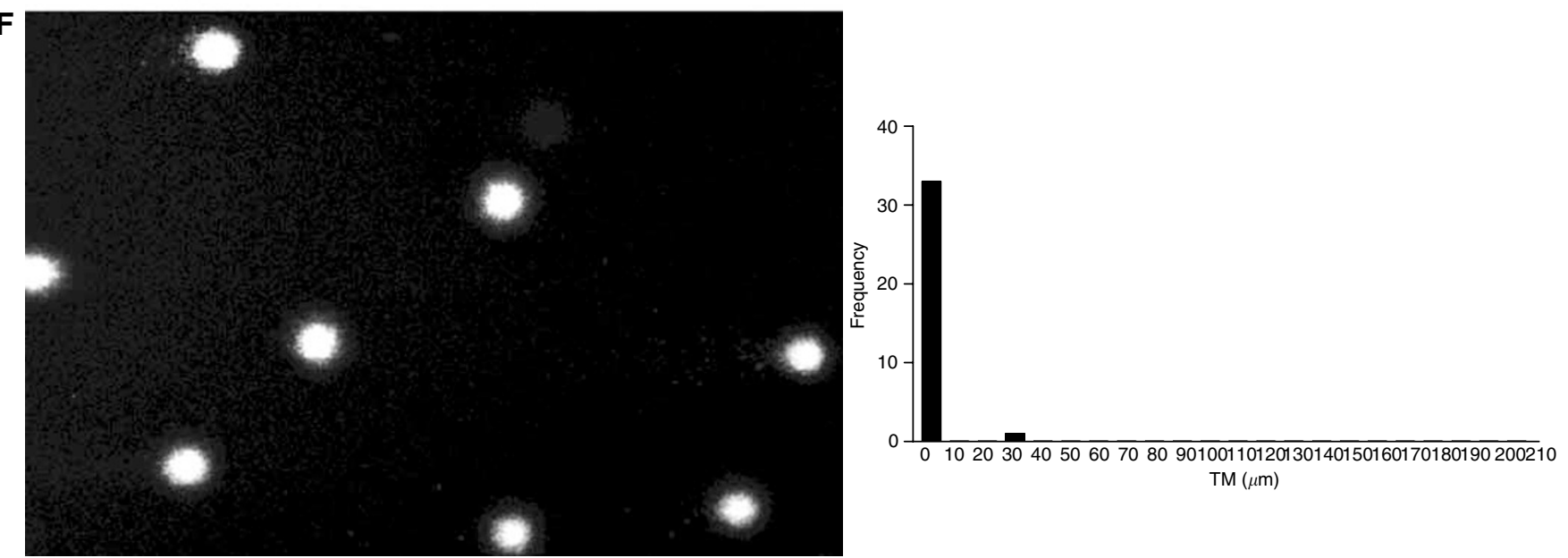

Figure 2 (Continued)

apply the method to the clinical samples were not successful (data not shown).

The pharmacokinetics and metabolism of IFO determined in the 19 patients studied here are very similar to previous reports in paediatric patients (Boddy et al, 1993, 1995b; Boos et al, 1995; Kerbusch et al, 2001b). As has been reported previously, there were no systematic differences between patients treated with a continuous infusion compared to fractionated dosing (Boddy et al, 1995b; Boos et al, 1995). Induction of metabolism, detected as a decrease in plasma IFO concentration during infusion or on successive days of treatment, was apparent in most patients. This is accounted for largely by an increase in metabolism to inactive dechloroethylated metabolites (Boddy et al, 1995a; Kerbusch et al, 2001b, c).

The distribution of TMs seen in the pretreatment PBL samples indicated that the method used was selective for DNA damage 


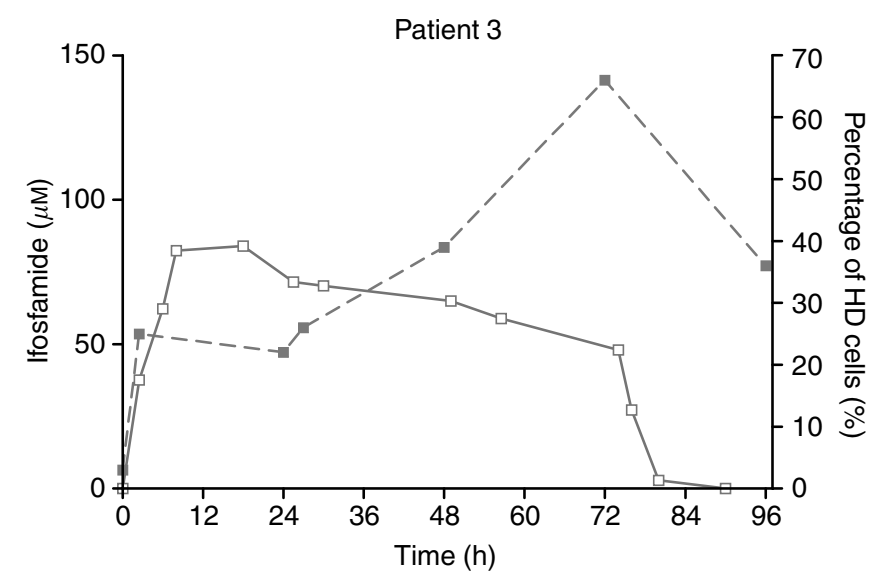

Figure 3 Time course of IFO concentration (solid line) and DNA damage (dotted line) as detected by the COMET assay in patient 3, who was treated with a $72 \mathrm{~h}$ continuous infusion. DNA damage quantified as the percentage of damaged cells in $\mathrm{PBL}$ samples.

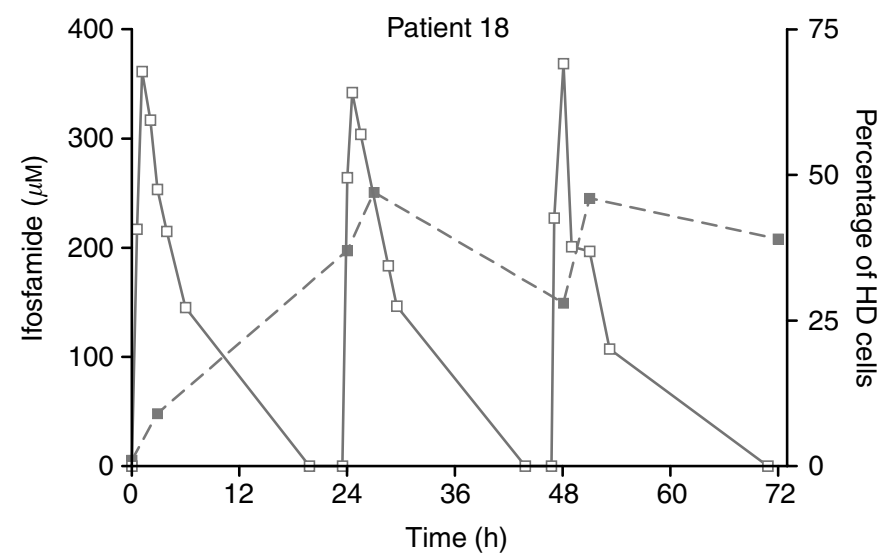

Figure 4 Time course of IFO concentration (solid line) and DNA damage (dotted line) as detected by the COMET assay in patient 18, who was treated with a $3 \mathrm{~h}$ infusion on 3 consecutive days. DNA damage quantified as the percentage of damaged cells in PBL samples.

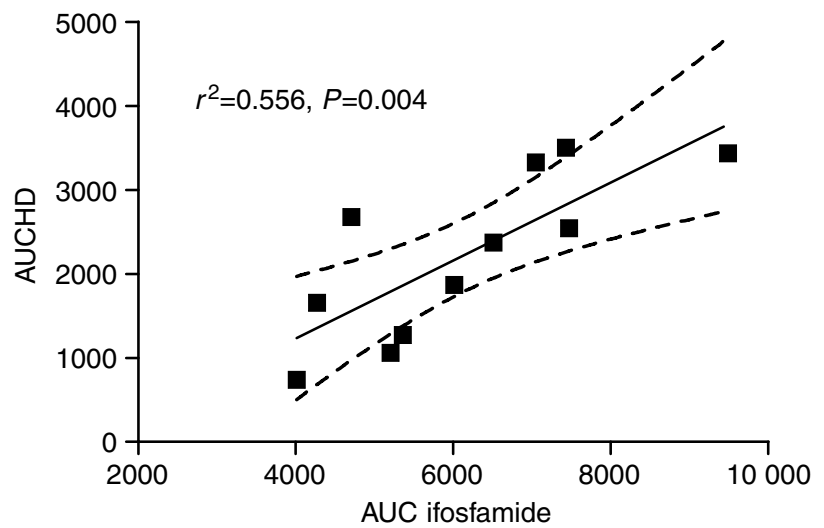

Figure 5 Plot of area under the curve for highly damaged cells $(A \cup C H D)$ against plasma area under the concentration-time curve for IFO for those patients who received fractionated infusions over 3 days. Line indicates regression, with $95 \%$ confidence intervals. AUC for IFO in $\mu \mathrm{Mh}^{-1}$. AUCHD units are $\% \times$ hours.

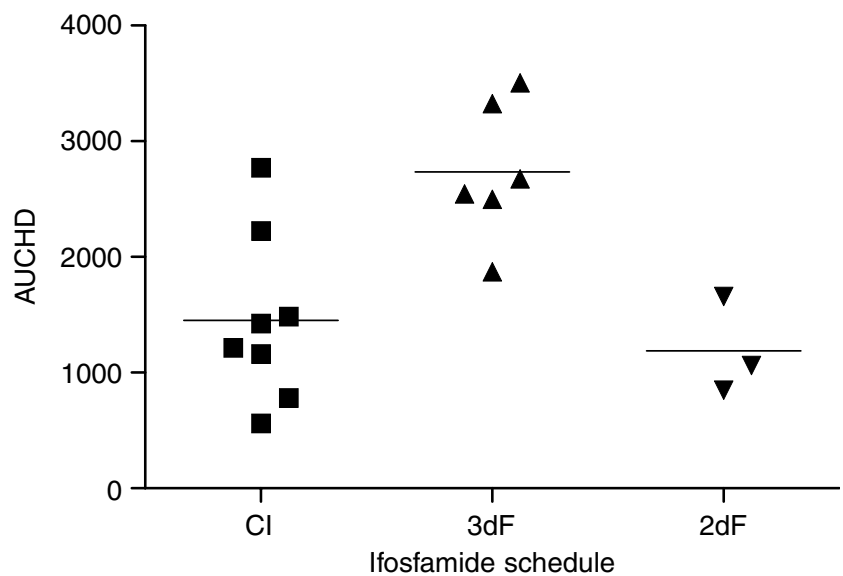

Figure 6 Comparison of summary measure of DNA damage (AUCHD) according to whether IFO was administered at a dose of $3 \mathrm{~g} \mathrm{~m}^{-2}$ day ${ }^{-1}$ by continuous infusion over 3 days, by fractionated infusions over 3 days or fractionated infusion over 2 days. AUCHD units are $\% \times$ hours.

Table 3 AUCHD for CCR-CEM cells treated with IPM or 4-hydroxy$\mathrm{IFO}$ in vitro

\begin{tabular}{|c|c|c|}
\hline & Treatment & AUCHD \\
\hline In vitro & $\begin{array}{l}\text { IPM IC } C_{50} \\
\text { IPM } 4 \times I_{50} \\
\text { 4-hydroxy-IFO IC } 50 \\
\text { 4-hydroxy-IFO } 4 \times I_{50}\end{array}$ & $\begin{array}{l}1399 \pm 147 \\
2549 \pm 395 \\
2850 \pm 407 \\
3185 \pm 819\end{array}$ \\
\hline Clinical data & $\begin{array}{l}\text { IFO continuous infusion } \\
\text { IFO } 3 \times \text { daily infusion } \\
\text { IFO } 2 \times \text { daily infusion }\end{array}$ & $\begin{array}{l}1453 \pm 730 \\
2736 \pm 597 \\
1190 \pm 419\end{array}$ \\
\hline
\end{tabular}

$\mathrm{AUCHD}=$ area under the curve of \% highly damaged cells; IPM = isophosphoramide mustard. For comparison, AUCHD data are also shown for patients treated with either continuous infusion or fractionated dosing of ifosfamide. AUCHD given as mean \pm s.d. Units are $\% \times$ hours.

caused by the administration of chemotherapy. One patient, a 19year-old smoker, had a slightly shifted distribution of TMs and a greater number of detectable HD cells. However, increases above background in both TM distribution and percentage HD were seen in this patient, as with the other patients studied. Figures 1 and 2 show the evolution of DNA damage, as detected by the COMET assay, before, during and after IFO administration and Figures 3 and 4 overlay the DNA damage data with plasma concentrationtime curves for individual patients.

In order to understand the relationship between DNA damage and the systemic pharmacology of IFO, a summary measure of DNA damage AUCHD was plotted against pharmacokinetic parameters for IFO and AUC values for its metabolites. The only significant correlation was found between AUCHD and AUC for IFO itself, and then only for those patients where IFO was administered as fractionated infusions over 3 days. This is in contrast to previous reports on cyclophosphamide, where either antitumour effect or toxicity has been found to be inversely related to plasma AUC for the parent drug (or positively correlated to clearance) (Ayash et al, 1992; Yule et al, 2004). This discrepancy in the data for these two related drugs, which are thought to share a common mechanism of action, may relate to the differing contributions of activating and inactivating pathways of metabolism (Boddy and Yule, 2000). Cyclophosphamide elimination is largely due to metabolism via the initial 4-hydroxylation of the 
oxazaphosphorine ring. Only $5 \%$ or less of the metabolism of the parent drug is via the inactivating dechloroethylation pathway (Moore, 1991). In contrast, $50 \%$ of the metabolism of IFO is by dechloroethylation and up to $23 \%$ of a dose is eliminated unchanged in the urine (Kerbusch et al, 2001a), suggesting that elimination of parent drug reflects inactivation for IFO. We have previously reported a weak correlation between DNA damage and plasma concentrations of the 4-hydroxy metabolite of IFO, although this unstable metabolite was only measurable in four patients (Johnstone et al, 2000). The fact that a weak correlation was seen in the present study between AUCHD and AUC for carboxy-IFO, which is formed by sequential metabolism of 4hydroxy-IFO, may suggest that detection of the carboxy metabolite in plasma largely reflects activation of the parent drug.

Comparisons of IFO administered either as a $72 \mathrm{~h}$ continuous infusion or as a short infusion on 3 consecutive days showed no consistent difference in the either the metabolism or the clearance of the parent drug (Boddy et al, 1995b; Boos et al, 1995). Data from the study reported here, without the within-subject crossover of previous studies, again indicated no difference in the systemic pharmacology of IFO between the two schedules. However, there was a significant difference between the two schedules of administration with regard to the degree of damage in PBL. The mean AUCHD was 2497 for the fractionated dosing over 3 days, whereas that seen following the continuous infusion was 1453 . A lower AUCHD (mean 1190) was observed following 2 days of fractionated dosing. This difference in pharmacological effect between the two schedules suggests that the fractionated dosing schedule may be more effective, perhaps with a greater risk of

\section{REFERENCES}

Ayash LJ, Wright JE, Tretyakov O, Gonin R, Elias A, Wheeler C, Eder JP, Rosowsky A, Antman K, Frei E (1992) Cyclophosphamide pharmacokinetics: correlation with cardiac toxicity and tumor response. J Clin Oncol 10: $995-1000$

Boddy AV, Cole M, Pearson ADJ, Idle JR (1995a) The kinetics of the autoinduction of ifosfamide metabolism during continuous-infusion. Cancer Chemother Pharmacol 36: 53-60

Boddy AV, English M, Pearson ADJ, Idle JR, Skinner R (1996) Ifosfamide nephrotoxicity: limited influence of metabolism and mode of administration during repeated therapy in paediatrics. Eur J Cancer 32A: $1179-1184$

Boddy AV, Idle JR (1992) Combined thin-layer chromatography photography densitometry for the quantification of ifosfamide and its principal metabolites in urine, cerebrospinal-fluid and plasma. J Chromatogr Biomed Appl 575: $137-142$

Boddy AV, Yule SM (2000) Metabolism and pharmacokinetics of oxazaphosphorines. Clin Pharmacokinet 38: 291-304

Boddy AV, Yule SM, Wyllie R, Price L, Pearson ADJ, Idle JR (1993) Pharmacokinetics and metabolism of ifosfamide administered as a continuous-infusion in children. Cancer Res 53: 3758-3764

Boddy AV, Yule SM, Wyllie R, Price L, Pearson ADJ, Idle JR (1995b) Comparison of continuous-infusion and bolus administration of ifosfamide in children. Eur J Cancer 31A: 785-790

Boos J, Silies H, Hohenlochter B, Jurgens H, Blaschke G (1995) Short-term versus continuous infusion: no influence on ifosfamide side-chain metabolism. Eur J Cancer 31A: 2417-2418

Breneman JC, Lyden E, Pappo AS, Link MP, Anderson JR, Parham DM, Qualman SJ, Wharam MD, Donaldson SS, Maurer HM, Meyer WH, Baker KS, Paidas CN, Crist WM (2003) Prognostic factors and clinical outcomes in children and adolescents with metastatic rhabdomyosarcoma a report from the intergroup rhabdomyosarcoma study IV. J Clin Oncol 21: $78-84$

Carli M, Passone E, Perilongo G, Bisogno G (2003) Ifosfamide in pediatric solid tumors. Oncology 65: 99-104

Dockham PA, Lee MO, Sladek NE (1992) Identification of human liver aldehyde dehydrogenases that catalyze the oxidation of aldophosphamide and retinaldehyde. Biochem Pharmacol 43: 2453-2469 toxicity. The mechanism underlying this difference may relate to changes in enzyme levels during continuous exposure to parent drug, or might reflect changes in the activity of activating enzymes following exposure to toxic metabolites. There were insufficient numbers of patients with consistent treatment in this study to analyse any relationship to toxicity. Values of AUCHD observed in $\mathrm{PBL}$ in patients were similar to those associated with growth inhibition in vitro in CCRF-CEM cells.

The data reported here on DNA damage following IFO administration indicate, in a very heterogeneous patient population, that the COMET assay may provide useful information on the pharmacology of IFO. Fractionating the dose of IFO over 3 days appears to result in a greater degree of DNA damage than continuous infusion of the same dose. Also, for patients receiving IFO as a fractionated schedule, there was a direct correlation between overall DNA damage and the AUC of the parent drug. Further studies with patient groups receiving more uniform treatment should focus on the relationship between DNA damage and clinical outcome, and also incorporate measures of DNA crosslink formation (Hartley et al, 1999), in addition to the strand breaks as detected here. Clinical use of COMET analysis in PBLs requires further validation by comparison with tumour DNA damage or clinical outcome.

\section{ACKNOWLEDGEMENTS}

This research was supported by North of England Children's Cancer Research Fund and by Cancer Research UK.

Fairbairn DW, Olive PL, Oneill KL (1995) The comet assay - a compre hensive review. Mutat Res Rev Genet Toxicol 339: $37-59$

Hartley JM, Spanswick VJ, Gander M, Giacomini G, Whelan J, Souhami RL, Hartley JA (1999) Measurement of DNA cross-linking in patients on ifosfamide therapy using the single cell gel electrophoresis (COMET) assay. Clin Cancer Res 5: 507-512

Hininger I, Chollat-Namy A, Sauvaigo S, Osman M, Faure H, Cadet J, Favier A, Roussel AM (2004) Assessment of DNA damage by comet assay on frozen total blood: method and evaluation in smokers and non-smokers. Mutat Res Genet Toxicol Environ Mutagen 558: $75-80$

Johnstone EC, Lind MJ, Griffin MJ, Boddy AV (2000) Ifosfamide metabolism and DNA damage in tumour and peripheral blood lymphocytes of breast cancer patients. Cancer Chemother Pharmacol 46: $433-441$

Kamen BA, Frenkel E, Colvin OM (1995) Ifosfamide - should the honeymoon be over. J Clin Oncol 13: 307-309

Kerbusch T, de Kraker J, Keizer HJ, van Putten JWG, Groen HJM, Jansen RLH, Schellens JHM, Beijnen JH (2001a) Clinical pharmacokinetics and pharmacodynamics of ifosfamide and its metabolites. Clin Pharmacokinet 40: $41-62$

Kerbusch T, de Kraker J, Mathot RAA, Beijnen JH (2001b) Population pharmacokinetics of ifosfamide and its dechloroethylated and hydroxylated metabolites in children with malignant disease - a sparse sampling approach. Clin Pharmacokinet 40: 615-625

Kerbusch T, Mathot RAA, Keizer HJ, Kaijser GP, Schellens JHM, Beijnen $\mathrm{JH}$ (2001c) Influence of dose and infusion duration on pharmacokinetics of ifosfamide and metabolites. Drug Metab Dispos 29: 967-975

Kerbusch T, Mathot RAA, Keizer HJ, Ouwerkerk J, Rodenhuis S, Schellens JHM, Beijnen JH (2001d) Population pharmacokinetics and exploratory pharmacodynamics of ifosfamide and metabolites after a 72-h continuous infusion in patients with soft tissue sarcoma. Eur J Clin Pharmacol 57: $467-477$

Misiura K, Zubowska M, Zielinska E (2003) Analysis of the urinary excretion of ifosfamide and its $\mathrm{N}$-dechloroethylated metabolites in children using P-31-NMR spectroscopy. Arzneimittel-Forschung 53: $372-377$ 
Moore MJ (1991) Clinical pharmacokinetics of cyclophosphamide. Clin Pharmacokinet 20: $194-208$

Rojas E, Lopez MC, Valverde M (1999) Single cell gel electrophoresis assay: methodology and applications. J Chromatogr B 722: 225 - 254

Silies H, Blaschke G, Hohenlochter B, Rossi R, Jurgens H, Boos J (1998) Excretion kinetics of ifosfamide side-chain metabolites in children on continuous and short-term infusion. Int J Clin Pharmacol Therap 36: $246-252$

Sladek N (1988) Metabolism of oxazaphosphorines. Pharmacol Therap 37: $301-355$

Vela-Ojeda J, Tripp-Villanueva F, Montiel-Cervantes L, Sanchez-Cortes E, Ayala-Sanchez M, Guevara-Moreno ME, Garcia-Leon LD, Rosas-Cabral A, Esparza M, Gonzalez-Llaven J (2000) Prospective randomized clinical trial comparing high-dose ifosfamide plus GM-CSF $v s$ high-dose cyclophosphamide plus GM-CSF for blood progenitor cell mobilization. Bone Marrow Transplant 25: 1141 - 1146

Wainer IW, Ducharme J, Granvil CP, Trudeau M, Leyland-Jones B (1994) Ifosfamide stereoselective dechloroethylation and neurotoxicity. Lancet 343: $982-983$

Walker D, Flinois JP, Monkman SC, Beloc C, Boddy AV, Cholerton S, Daly AK, Lind MJ, Pearson ADJ, Beaune PH, Idle JR (1994) Identification of the major human hepatic cytochrome-P450 involved in activation and N-dechloroethylation of ifosfamide. Biochem Pharmacol 47: 1157-1163

Yule SM, Price L, McMahon AD, Pearson ADJ, Boddy AV (2004) Cyclophosphamide metabolism in children with non-Hodgkin's lymphoma. Clin Cancer Res 10: $455-460$ 